\title{
Effects of Tetrahydropalmatine (THP) on PTSD-induced Changes in Rat Neurobehavior
}

\author{
Tomás Eduardo Ceremuga, Rachel Anderson, Peter Frye, Christopher Duvall, Jason Maan, \\ Christopher Manjarres, Julie Petsche, George A. Ceremuga \& Michael Bentley
}

\begin{abstract}
The purpose of this study was to investigate tetrahydropalmatine (THP), a major compound in Corydalis yanhusuo WT Wang (Family: Papaveraceae) and its effects on PTSD induced neurobehavior in the rodent model. The aims were to determine the effects of THP on anxiety, locomotion, and memory. A prospective experimental between groups design was used. Eighty rats were randomly divided into two groups, nonstressed and stressed. They were then randomly subdivided into four groups: control, THP, midazolam, or THP and midazolam. The behavioral component was evaluated using the elevated plus maze (EPM) and Morris water maze (MWM) in a restraint/shock stress model. Data analysis was performed using a two-tailed Multivariate Analysis of Variance (MANOVA) and LSD post-hoc test. There were significant differences in anxiety between the groups $(P<0.05)$. The PTSD stressed rat groups had significantly reduced time on the open arms of the EPM demonstrating significant increased anxiety compared to the control nonstressed groups. Data pertaining to the MWM did not demonstrate
\end{abstract}

Received: 2 January 2014 / Accepted: 4 February 2014 / Published online: 9 February 2014

(C) Horizon e-Publishing Group

CITATION

Ceremuga, T.E., Anderson, R., Frye, P., Duvall, C., Maan, J., Manjarres, C., Petsche, J., Ceremuga, G.A., and Bentley, M. (2014). Effects of Tetrahydropalmatine (THP) on PTSD-induced Changes in Rat Neurobehavior. Plant Sci. Today, 1(1), 22-32. http://dx.doi.org/10.14719/pst.2014.1.1.12

Tomás Eduardo Ceremuga*, Rachel Anderson, Peter Frye, Christopher Duvall, Jason Maan, Christopher Manjarres, Julie Petsche, and Michael Bentley - US Army Graduate Program in Anesthesia Nursing/Northeastern University, USA.

George A Ceremuga - University of South Dakota, USA

*Corresponding Author: Tomás Eduardo Ceremuga, CRNA, PhD., AMEDDC\&S Nursing Science, ATTN: Thomas E. Ceremuga, 3490 FORAGE RD; STE 112, FT SAM HOUSTON TX 78234-7585. Comm: (210) 833-0786. Email: Thomas.E.Ceremuga.civ@mail.mil statistical significance. While a one-time dose of THP was insufficient in providing a significant decrease in anxiety, a multi-dose regimen may yield more effective results. Future experiments should evaluate a multi-dose or prophylactic regimen.

Key words: Post traumatic stress disorder; PTSD; Tetrahydropalmatine; THP; Neurobehavior; Rat.

\section{Introduction}

Post-traumatic stress disorder (PTSD) is one of the most common and devastating emotional injuries associated with war. Since 2008, the Military Health System (MHS) has recorded over 40,000 patients who have this emotional illness (Shiner, 2012). The emotional and physiological symptoms of PTSD are complex and very harmful to the health of military troops and their families. PTSD often results in symptoms of nervousness, memory problems, and hypervigilant responses. Since PTSD is very complicated, current treatments are also complicated. No one treatment has been found to be perfect. Furthermore, various treatments continue to change with additional therapies that include psychologists, behavior modifications, family involvement, and the use of medications.

Herbal medications have become a significant alternative to traditional medicines. The use of herbal medicine increased 380\% in the U.S. between 1990 and 1997 (Ang-Lee, Moss, \& Yuan, 2001). Corydalis yanhusuo, a popular perennial herb belonging to the Papaveraceae family has been found to decrease nervousness and movement in the laboratory rat. Because PTSD is categorized as an anxiety or nervousness disorder (Jankowsi, 2010), it is important to study the potential benefits of these herbal medications in the treatment of PTSD. This experiment examined tetrahydropalmatine (THP), a major compound in C. yanhusuo, on behaviors in rats with PTSD. Using the laboratory rat in experiments, these studies examined the possible benefits of THP. 
The animal testing instruments, (Morris water maze and elevated plus maze) were used to examine the possible beneficial effects of THP on nervousness, movement, and memory. This study also examined whether THP interacted with a frequently administered anxiolytic medication, midazolam. Active duty military, reservists, veterans, and the general public exposed to stressful, traumatic circumstances, could benefit from the knowledge obtained from this research.

\section{Background}

PTSD is a complex mental disorder that may develop in response to traumatic experiences and is defined in the Diagnostic and Statistical Manual (DSM)-Fourth EditionText Revised (DSM-IV-TR) as an anxiety disorder comprising four major criteria:

1. Exposure to or witnessing an event that is threatening to one's well-being and responding with intense fear, helplessness, or horror.

2. Symptoms of re-experiencing, such as recurrent and intrusive memories, nightmares, a sense of reliving the trauma, or psychological and physiological distress when reminded of aspects of the trauma.

3. Avoidance of thoughts, feelings, or reminders of the trauma, and the inability to recall parts of the trauma, withdrawal, and emotional numbing.

4. Arousal increases, as manifested in sleep disturbance, irritability, difficulty concentrating, hypervigilance (hyperarousal), or exaggerated startle response.

These symptoms must persist for at least one month after the traumatic event and result in a deficit in function (American Psychiatric Association, 2000). PTSD can also result in cognitive deficits that impair concentration, decision making, and memory. Interpersonal relations are often strained with conflict, social withdrawal and alienation, reduced intimacy, and impaired work performance. Furthermore, there are often somatic complaints of exhaustion, insomnia, headaches, startle response, hyperarousal, cardiovascular, gastrointestinal, and musculoskeletal disorders (Jankowsi, 2010).

After a traumatic experience, a number of individuals suffer distress, mental illness, and/or PTSD (Ursano et al., 2009). Simply stated, PTSD is the inability to forget the traumatic events resulting in pathology and distress. When PTSD symptoms present, treatment is required which includes psychotherapeutic and often pharmacologic therapies. These therapies are implemented to treat the symptoms of PTSD, which include intrusive thoughts or nightmares, anxiety, avoidance of situations similar to the traumatic event, and hyperarousal or startle (Ursano et al., 2009). An assembly of professionals from the American Psychiatric Association developed and published practice guidelines for the treatment of PTSD (Ursano et al., 2009). They concluded that there is In a recent evidence-based review of these guidelines, the American Psychiatric Association suggests that there is a need for more effective pharmacological treatments, especially for veterans with combat-related PTSD (Benedek, 2009).

\section{Review of Literature}

\section{Benzodiazepines (Midazolam)}

Benzodiazepines are frequently administered to patients for anxiolysis. They are used as an anticonvulsant and muscle relaxant. Their predominant clinical use has been for the treatment of anxiety (Nutt \& Malizia, 2001). Benzodiazepines produce anxiolysis and antegrade amnesia and are frequently administered to patients perioperatively. Benzodiazepines are the most commonly prescribed anxiolytic drugs in the United States, and many patients are on long-term benzodiazepine therapy (Shader \& Greenblatt, 1993). According to the American Psychiatric Association guidelines, benzodiazepines are viewed as possibly effective for anxiety and insomnia but may have a negative impact on PTSD (Benedek, 2009).

\section{Incidence of Herbal Supplement Use}

Complementary and alternative medicines (CAM) which includes herbal supplements are frequently used by military service personnel and their families. A study of US Navy and Marine Corps personnel reported that 37\% use CAM with $15.9 \%$ taking herbal supplements (Smith et al., 2007). Similarly, a survey of Army soldiers, retirees, and family members at an Army Medical Center demonstrated a $36 \%$ use of herbal supplements (McPherson \& Schwenka, 2004). Herbal supplement use has increased rapidly as alternative treatments have multiplied exponentially. When compared to previous studies, current research indicates that $40 \%$ of U.S. consumers use herbal products, representing a $25 \%$ increase in a seven year period (Eisenberg et al., 1998).

Many Americans are using herbal supplements in lieu of pharmaceuticals to treat their maladies. This is a result of an increase in public enthusiasm for alternative herbal medications in recent years. In 1997, $12 \%$ of the U.S. population reported using herbal medications, represent 380\% increase since 1990 (Ang-Lee et al., 2001).

Although there is a burgeoning of herbal supplement use, controls and standardization are lacking. According to the Dietary Supplement Health and Education Act of 1994, there is no requirement for evidence of efficacy, safety, or quality control standards for supplements. This absence of control increases the risk of adverse effects related to herbal supplements (Sabar, Kaye, \& Frost, 2001). The National Institute of Health estimates that approximately $40 \%$ of American adults and approximately 12\% of children used alternative medical treatments within the 
past 12 months (Barnes, 2008). Up to $72 \%$ out of 1,539 adults surveyed regarding their alternative therapies, including herbal use, do not disclose their treatment to healthcare providers, exacerbating the problem (Lambert, 2008). In fact, because this undisclosed use of herbal medications, the Joint Commission has mandated that healthcare providers screen and document patients' use of herbal medications at each health care visit (Joint Commission, 2010). This lack of data demonstrates the need for scientific research concerning herbal medications and the possible adverse effects and interactions with perioperative medicines. Many herbal products can interact with frequently used medications, including anesthesia, and may cause serious unforeseen consequences or complications (Dorman, 2001; Kaye, Kucera, \& Sabar, 2004; Lee, Chui, Aun, Lau, \& Gin, 2006).

\section{Need for Research}

While herbals have numerous purported benefits, there are no scientific reports regarding their possible pharmacologic and therapeutic benefits in PTSD. Patients with mental health conditions such as insomnia, depression, and anxiety turn to herbal supplements in an attempt to self-medicate. C. yanhusuo is an herbal medication/dietary supplement that warranted investigation for its purported anxiolytic/calming effects secondary to limited scientific data concerning its action.

\section{Corydalis yanhusuo/Tetrahydropalmatine (THP)}

Corydalis yanhusuo is a traditional Chinese herbal medicine that has speculated analgesic properties $(\mathrm{Hu}, \mathrm{Xie}$, Zhang, Wang, \& Chen, 1994), antiseizure activity (Chang \& Lin, 2001; Lin, Wang, \& Young, 2002); antihypertensive effects (Chan, Chiu, Chen, Wu, \& Cheng, 1999; Lin, Chueh, Hsieh, \& Chen, 1996); and sedative/hypnotic effects (Zhu, 1991). It appears that tetrahydropalmatine (THP) is the biologically active extract (Hong et al., 2006) and has been demonstrated to have antiseizure properties by reducing the seizure activity of kindled rats (Lin et al., 2002). THP may also be responsible for the antihypertensive properties of $C$. yanhusuo, as it has been shown to antagonize dopamine- 2 receptors in the hypothalamus resulting in hypotension and bradycardia (Chueh, Hsieh, Chen, \& Lin, 1995; Lin et al., 1996). Recently, our lab demonstrated a significant anxiolytic effect and decrement in motor movements with the administration of tetrahydropalmatine (THP), a component isolated from $C$. yanhusuo in the laboratory rat (Henkes et al., 2011). Currently, gene expression changes have been shown in dopamine, serotonin, acetylcholine, and gammaaminobutyric acid neurotransmitter systems when THP was administered in a PTSD rodent model (Ceremuga et al., 2013). Although there is evidence of central nervous system modulation, there are no studies evaluating the potential therapeutic properties of THP or C. yanhusuo in PTSD.
There is a large void of research that definitively describes the pharmacodynamic site, or sites, that produce the mechanism of action of THP and its resultant behavioral effects. It was critically important to determine if herbal supplements, like THP, are effective pharmacologic agents in decreasing the negative neurobehavioral symptoms of PTSD.

\section{Background on PTSD Rodent Model}

There are various documented rodent PTSD models developed to determine the molecular mechanism(s) of PTSD. As reviewed by Lei Zhang (Zhang et al., 2006), these animal models have been developed in which extremely stressful experiences, aversive challenges, and situational reminders of a traumatic stress have demonstrated longterm effects on behavioral, autonomic, and hormonal responses that are in parallel with many of the changes seen in humans with PTSD. Among these models, inescapable tail-shock model of traumatic stress, an animal model of PTSD modified from the learned helplessness paradigm, has been shown to mimic PTSD in terms of certain physiological parameters (Garrick, Morrow, Shalev, \& Eth, 2001; Servatius, Ottenweller, \& Natelson, 1995). Several laboratories have successfully established and tested the inescapable tail-shock model of stress in rats and verified that the behavioral and neurobiological alterations induced by this rat model are similar to those found in PTSD patients (Garrick et al., 2001; Servatius et al., 1995).

\section{Objective}

There are no data regarding the effectiveness of herbal supplements in the treatment of PTSD. Furthermore, no research exists on the effects of $C$. yanhusuo on PTSD. Our hypothesis was that administration of THP may improve neurobehavior in the PTSD rat model and our goal was to further corroborate this stringent PTSD rodent model. The objectives/specific aims of this study were to determine the effects of THP in a PTSD rodent model and confirm this PTSD model.

\section{Theoretical Framework}

The theoretical framework of this study was the integration of the evaluation of neurobehavioral effects of THP in PTSD. A 3-day restraint/shock stress induces PTSD. Herbal treatment with THP results in amelioration of neurobehavioral symptoms; i.e. decreased anxiety by increased time on open arms on EPM and increased memory on the Morris water maze instrument (see Figure 1).

\section{Operational Definitions}

Three major neurobehavioral symptoms of PTSD are anxiety, motor movement, and memory deficit and were investigated in the rodent model. 


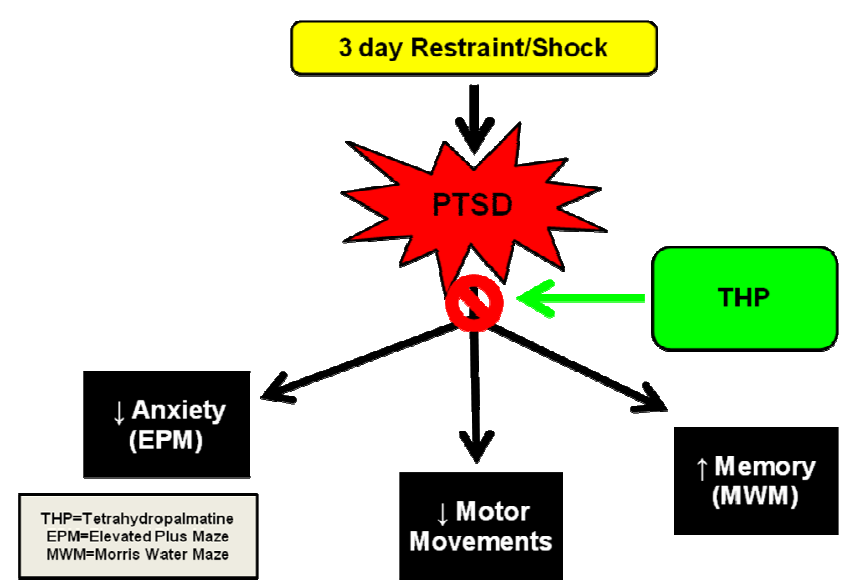

Figure 1. Theoretical Framework illustrating the relationship between traumatic event (3 day restraint/shock) and tetrahydropalmatine (THP) on the development of PTSD symptoms: anxiety, motor movement, and memory. $\mathrm{EPM}=$ Elevated plus maze; MWM = Morris water maze

For the purposes of this study, the following operational definitions were used:

1. PTSD is defined as a condition that results from rats being exposed to three days of a stress regimen exposure consisting of a two hour per day session of immobilization and tail-shocks for three consecutive days (3DS) (2-hr sessions of 40, $2 \mathrm{~mA}$ tailshocks). Previous studies indicate that rats exposed to this stimuli have exhibited a consistent pattern of persistent physiological and behavioral abnormalities including an exaggerated startle response 10 days after stressor cessation and reduced body weight similar to PTSD (Servatius et al., 1995).

2. Anxiety is defined as the ratio of open arm time to total time on the elevated plus maze (EPM). A rat was considered to have entered an arm via the MotorMonitor software. At the end of the test, the time spent on the open arms was expressed as a percentage of the time spent on both the open and the closed arms. An increase in the percentage of time spent in the open arms reflects decreased anxiety.

3. Locomotion is defined as motor movements on the EPM. The EPM is networked with MotorMonitor software (Hamilton-Kinder, Poway, California) with laser sensors integrally attached to the EPM to track the number of entries into each arm, time spent in each arm, and total basic and fine motor movements. Basic motor movements are the simple count of beam breaks in the elevated plus maze. Each time a photobeam is interrupted, the basic movement count is increased. These movements reveal a gross measure of locomotion, but do not distinguish what type of activity is being performed. Fine motor movements are a compilation of small animal movements such as grooming, head weaves or bobs. When rats have increased anxiety or fear, they display freezing behaviors, or decreased movements (Flood, 2009; Servatius et al., 2005).

4. Memory is defined as spatial memory as tested using the Morris water maze (MWM). This task is based upon the premise that animals have evolved an optimal strategy to explore their environment and escape from the water with a minimum amount of effort - i.e., swimming the shortest distance possible. The time it takes a rat to find a hidden platform in a water pool after previous exposure to the setup, using only available external cues, is determined as a measure of spatial memory (Wenk, 2004).

\section{Materials and methods}

A prospective, between-subjects experimental design in the rodent model was used to investigate the aims of this study. The use of laboratory rats in this study was in accordance with the National Institutes of Health Guide for the Care and Use of Laboratory Animals and received Institutional Animal Care and Use Committee approval from the United States Army Institute of Surgical Research, Fort Sam Houston, Texas.

\section{Animals}

Eighty male Sprague-Dawley rats (Harlan SpragueDawley Laboratories) weighing 300-350 grams were used. They were housed in groups of three in polycarbonate 'shoebox' cages lined with bedding and underwent a habituation/adaptation period for 7 days in a temperature-controlled environment $\left(22+1^{\circ} \mathrm{C}, \quad 60 \%\right.$ humidity) with a light-dark cycle, receiving 12 hours of light ( 0600 hours to 1800 hours) and 12 hours of darkness (1800 hours to 0600 hours). They were allowed free access to food and water. The animals were handled for weighing, drug administration, and cleaning of cages only and were naïve to the EPM apparatus.

\section{Sample Size}

Rats were randomly assigned to one of eight groups of ten rats. Rats were assigned to the non-stressed groups or the 3-day restraint shock PTSD rodent model groups. There were four groups within the non-stressed rats (control, THP, midazolam, and midazolam + THP) and four groups in the stressed rats (control, THP, midazolam, and midazolam + THP) (see Table 1).

\section{Instruments}

\section{3-day Restraint/Tail Shock PTSD Model}

Forty animals assigned to the PTSD groups underwent the 3-day restraint/shock stress, which consisted of a 2 hour per day session of immobilization and tail-shocks for 3 consecutive days. The animals were stressed in the morning (between 0800 and 1200 hours). They were restrained in a plexiglas tube, and 40 electric shocks $(2 \mathrm{~mA}$, 3 s duration) were applied at varying intervals (140-180 
s). Rats were stressed for 3 consecutive days as it has been previously demonstrated that repeated stress sessions for 3 days is more effective than a single stress session in when exposed to urine and feces. The elevated plus maze is shaped like a cross (+), with the intersection of the four arms measuring 10 x $10 \mathrm{~cm}$ (Pellow et al., 1985).

Table 1. Illustrates the assignment of 80 rats into the treatment groups both non-stressed and stressed.

\begin{tabular}{lcccc}
\hline & Vehicle & THP & Midazolam & Midazolam + THP \\
\hline Non-Stressed (Control) & $\mathrm{n}=10$ & $\mathrm{n}=9^{*}$ & $\mathrm{n}=9^{*}$ & $\mathrm{n}=9^{*}$ \\
Stressed (PTSD) & $\mathrm{n}=9^{*}$ & $\mathrm{n}=10$ & $\mathrm{n}=10$ & $\mathrm{n}=10$ \\
\hline
\end{tabular}

${ }^{*}$ Attrition of one rat in each group of these groups during the experiments.

Table 2. Overview of Experiment Design: Outlines the day-by-day progression of experiment design from day 1 to day 24 and tests completed on each day.

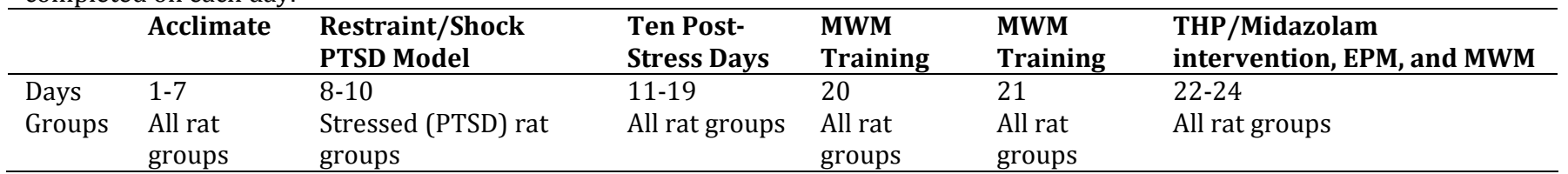

PTSD = Post Traumatic Stress Disorder, MWM = Morris water maze, EPM = Elevated plus maze.

producing physiological and behavioral abnormalities, such as reduced body weight (Servatius et al., 1995). All animals were tested 12-14 days following the 3-day restraint/shock stress on Days 22-24 (see Table 2).

Drugs

The drugs or vehicle were delivered by subcutaneous injection (1ml latex free syringe $\mathrm{w} / 27$ gauge $1 / 2$ inch needle, B-D, Franklin Lakes, NJ). Each animal received a subcutaneous ( $\mathrm{SQ}$ ) injection (10 rats/group) of: 1 . control (saline); 2. THP (Latoxan, France) $20 \mathrm{mg} / \mathrm{kg}$ (Lin et al., 2002); 3. midazolam (Versed $®$ ) $1.5 \mathrm{mg} / \mathrm{kg} ;$ or 4 . midazolam (Versed $囚$ ) $1.5 \mathrm{mg} / \mathrm{kg}+$ THP (to evaluate interaction effects). Midazolam, a known benzodiazepine, was used as a positive control for its established anxiolytic effects on the EPM. The control (saline) group acted as a control. All animals received equivalent volumes of subcutaneous injection to total $2 \mathrm{ml}$.

\section{EPM Apparatus}

The EPM is an instrument utilized to measure anxiety in the rodent model (U. Falter, Gower, \& Gobert, 1992; Lister, 1987; Rosa, Vandresen, Calixto, Kovaleski, \& Faria, 2000; Treit, Menard, \& Royan, 1993). This model has been validated in previous research studies (Pellow, Chopin, File, \& Briley, 1985).

The EPM consists of two open arms and two closed arms 50 centimeters $(\mathrm{cm})$ in length and $10 \mathrm{~cm}$ in width. The open arms are directly opposite of each other, and similarly the closed arms oppose one another. The open arm is covered with $1 \mathrm{~cm}$ high Plexiglas on the side, in order to prevent the rodent from falling. The maze was placed 50 centimeters above the floor. In addition to being constructed of wood, the interior floor was painted with waterproof epoxy paint in a dark color. This minimized rodent stimulation, and provided a waterproof surface
Thirty minutes after injection, each animal was placed in the center of the EPM, facing an open arm, and behavioral responses to anxiety were evaluated by the EPM for 5 minutes. The EPM was networked with MotorMonitor software (Hamilton-Kinder, Poway, California) with laser sensors integrally attached to the EPM, which tracked the number of entries into each arm, time spent in each arm, and total basic and fine motor movements. Basic motor movements are the simple count of beam breaks in the EPM. Each time a photo beam is interrupted the basic movement count is increased. These movements reveal a gross measure of locomotion but do not distinguish what type of activity is being performed. Fine motor movements are a compilation of small animal movements such as grooming, head weaves and bobs. In addition, each EPM session was videotaped and the data collected by the MotorMonitor were validated by a blind review of the taped sessions. The EPM was cleaned with soap and water and dried between each animal trial to limit variability related to previous rat scent on the maze.

The time spent on the open arms was also expressed as a percentage of the time spent on both the open and the closed arms. An increase in the percentage of time spent in the open arms reflected an anxiolytic effect.

\section{Morris Water Maze (MWM) Apparatus}

Specific aspects of spatial memory have been extensively studied using the Morris water maze. Animals have evolved an optimal strategy to explore their environment and escape from water using minimal effort. After previous exposure to the water maze setup and using only available external cues, the time it takes a rat to find a hidden platform in a pool of water is a measure of spatial memory (Wenk, 2004). With minor modifications, all animals were exposed to the two-day water maze test as previously described (Frick, Stillner, \& Berger-Sweeney, 
2000). In order to evaluate memory in rodents, the water maze test was utilized. The setup consisted of a circular $(190 \mathrm{~cm}$ in diameter) water-filled tank (up to $30 \mathrm{~cm}$ deep; temperature: $22 \pm 2{ }^{\circ} \mathrm{C}$ ) that was used for the test. A nontoxic dye was used to make the water opaque. The tank was divided into four zones. A platform $(18 \mathrm{~cm} \times 18 \mathrm{~cm})$ was submerged $2 \mathrm{~cm}$ below the water surface, in Zone 3 . The test was conducted in a small room where extra-maze cues were kept consistent throughout the experiment. An overhead camera was connected to a computer to record the data. Over two days, all the rats were exposed to the setup 12 times, for training purposes. A 30-minute interval separated two blocks of six swims. Each rat was given a total of 60 seconds to randomly explore the water maze and find the platform by chance. If the rat did not find the platform by chance, guidance was provided. The rat was then allowed ten seconds on the platform to familiarize itself to the location, relative to the available visual clues in the room. Each swim started from a designated position to maintain consistency for each rat. The data recorded included distance, mean speed, rotations, entries, time, latency to first entry and platform entries. The probe test involved removing the platform and a single trial of 60 seconds was performed on test day. The percentage of time spent in each zone was recorded. A sample trial where the rat swims in each zone of the Morris water maze and Zone 3, where the platform was located, is shown in Figure 2.

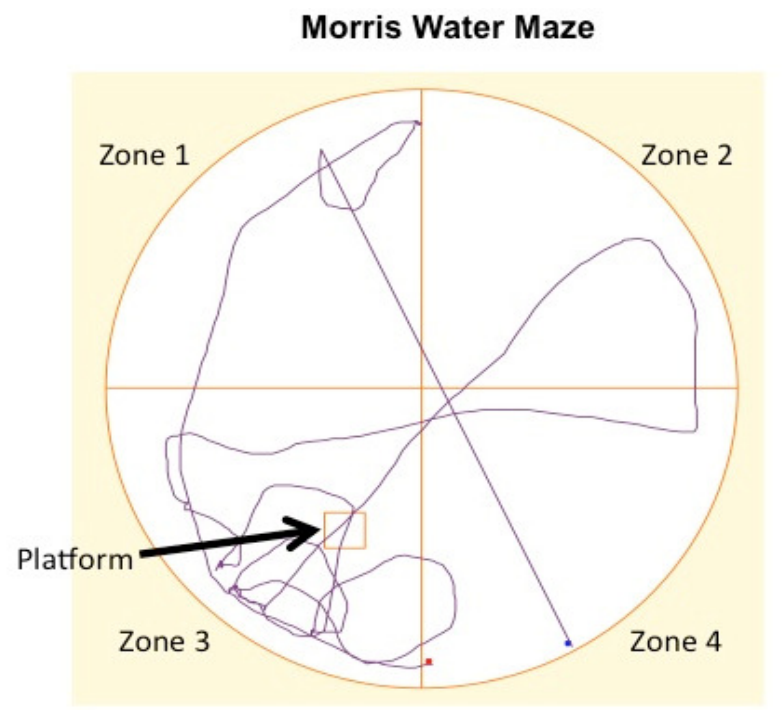

Figure 2. Map of the Morris water maze, as demonstrated from ANY-maze $®$ software. Zone 3 is the area where platform was located, and the line illustrates the path of rat searching for the platform.

\section{Statistical Analysis}

All neurobehavior data were analyzed using a two-tailed multivariate analysis of variance (MANOVA), using IBM ${ }^{\circledR}$ SPSS Statistics 21. All assumptions were examined including homogeneity of error variances (via the Levine test) and normality. A determination of statistical significance in neurobehavior using THP in a rodent model was made. If significance was found, a LSD post hoc was used (Glaser, 2010).

\section{Results}

Elevated Plus Maze

Data analyses were conducted using a 2-tailed multivariate analysis of variance and Least Significant Difference (LSD) post hoc test. Analysis of the ratio of open arm time versus total time spent in the elevated plus maze revealed statistically significant increases between the control midazolam and control vehicle group ( $\mathrm{P}=0.027)$; the control midazolam and control midazolam plus THP group ( $\mathrm{P}=0.017)$; the control midazolam and PTSD vehicle group $(\mathrm{P}=0.001)$; the control midazolam and PTSD THP group $(\mathrm{P}=0.006)$; and control midazolam and PTSD midazolam group $(\mathrm{P}=0.014)$. However, there was no significance found between the control THP and PTSD vehicle group $(\mathrm{P}=0.71)$ and the $\mathrm{PTSD}$ vehicle group compared to the PTSD THP group $(\mathrm{P}=0.530)$ (see Table 3 and Figure 3).

\section{Basic Motor Movements}

Total number of basic (gross) and fine motor movements tracked during time in the EPM were analyzed. Analysis showed a significant increase in basic motor movement of rats in the control vehicle group compared to the control THP group $(\mathrm{P}<0.001)$; the control midazolam group $(\mathrm{P}<0.001)$; the control THP plus midazolam group $(\mathrm{P}<0.001)$; the PTSD THP group $(\mathrm{P}<0.001)$; the PTSD THP group $(\mathrm{P}<0.001)$; the PTSD THP group $(\mathrm{P}<0.001)$; the PTSD midazolam group $(\mathrm{P}=0.003)$; and the PTSD midazolam plus THP group $(\mathrm{P}<0.001)$. Significant increase in basic movement of rats was also noted in the PTSD vehicle group compared to the control THP group $(\mathrm{P}<0.001)$; the control midazolam group $(\mathrm{P}<0.001)$; the control midazolam plus THP group $(\mathrm{P}<0.001)$; the PTSD THP group $(\mathrm{P}<0.001)$; the $\mathrm{PTSD}$ midazolam group $(\mathrm{P}=0.023)$; and the PTSD midazolam plus THP group $(\mathrm{P}<0.001)$. Significant increases in basic motor movements of rats were also noted in the control midazolam plus THP compared to the control THP group $(\mathrm{P}=0.046)$; the control midazolam plus THP group compared to the PTSD midazolam plus THP group $(\mathrm{P}=0.006)$; the PTSD midazolam group compared to the control THP $(\mathrm{P}<0.001)$; the PTSD midazolam compared to the control midazolam $(\mathrm{P}=0.007)$; the PTSD midazolam group compared to the control midazolam plus THP group $(\mathrm{P}=0.043)$; the PTSD midazolam group compared to the PTSD THP group $(\mathrm{P}<0.001)$; and the PTSD midazolam group compared to the PTSD midazolam plus THP $(\mathrm{P}<0.001)$ (see Table 3 and Figure 4). 


\section{Ratio Open-Arm Time to Total Time on Elevated Plus Maze}

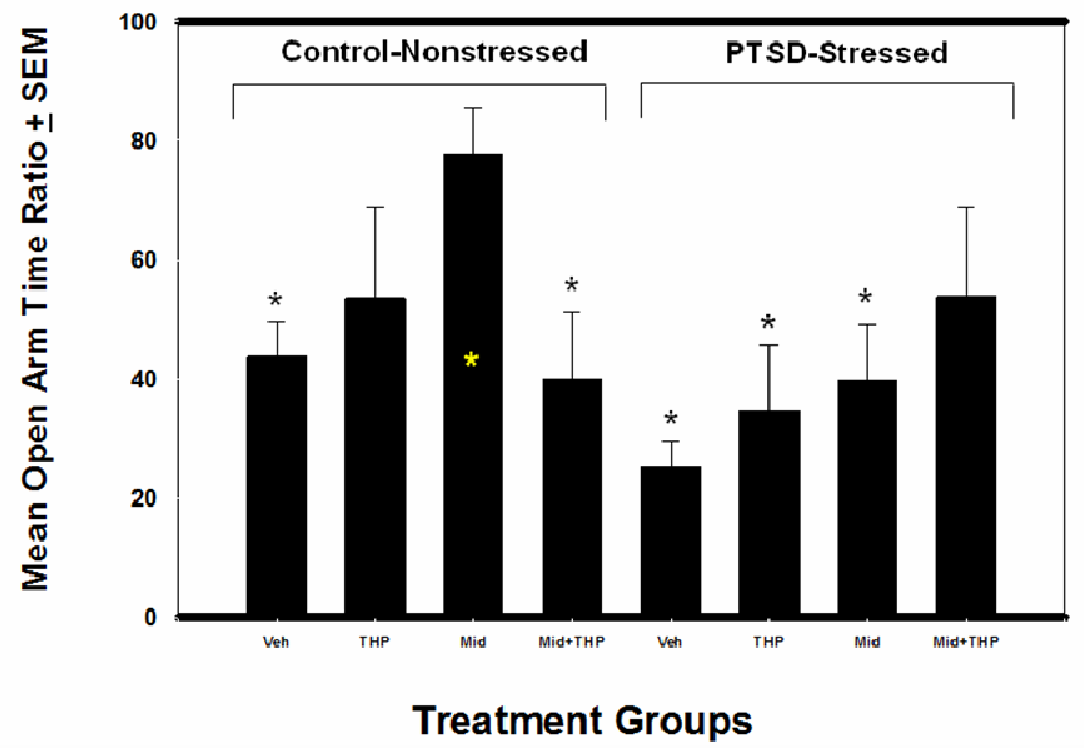

Figure 3. Bar graph representing the ratio of open-arm time to total time on Elevated Plus Maze. The X axis is the treatment groups and the $\mathrm{Y}$ axis shows the calculated ratio of the mean open-arm time to total time plus or minus the standard error of the mean in seconds. The asterisks show the groups that showed significance. Veh = Vehicle, THP = tetrahydropalmatine, Mid $=$ Midazolam, Mid+THP = Midazolam and tetrahydropalmatine, SEM = Standard Error of the Mean.

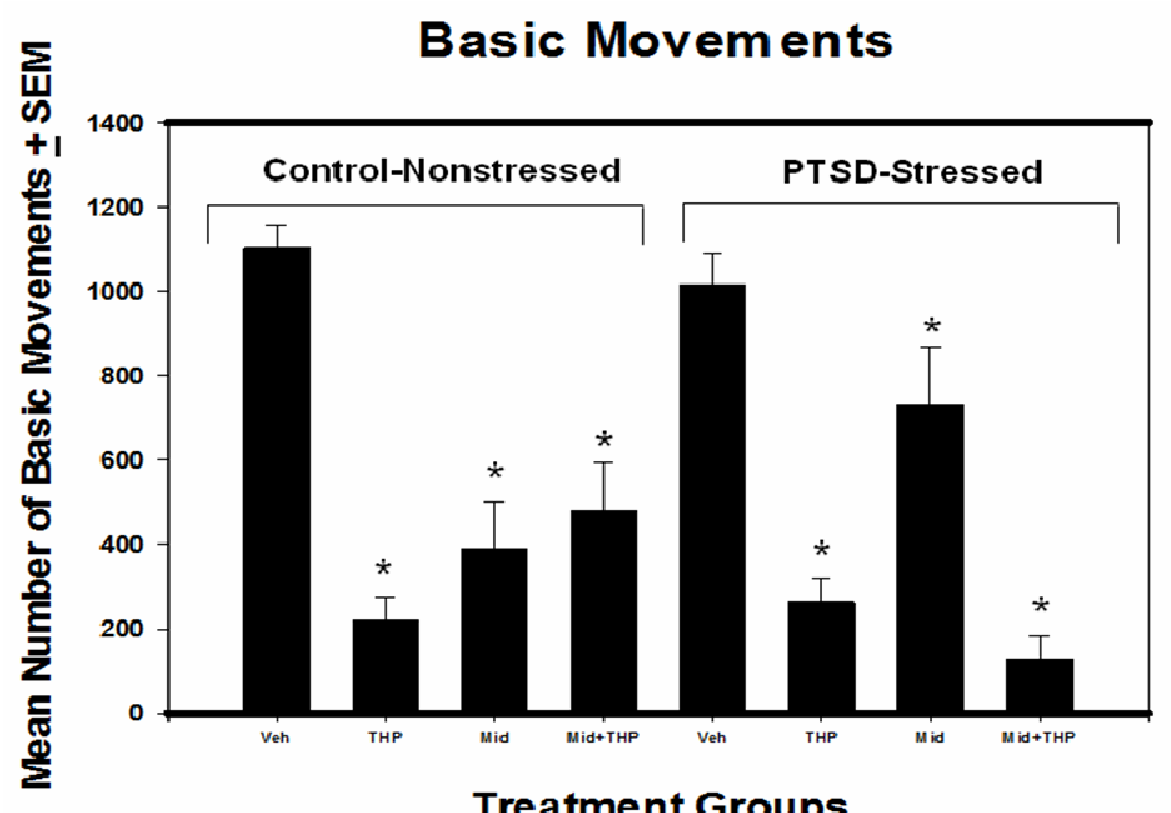

Figure 4. Bar graph representing the mean number of basic movements as recorded by the Motor monitor software on the Elevated Plus Maze. The $\mathrm{X}$ axis is the treatment groups and the $\mathrm{Y}$ axis shows the mean number of basic movements plus or minus the standard error of the mean. The asterisks show the groups that showed significance. Veh $=$ Vehicle, THP $=$ tetrahydropalmatine, Mid = Midazolam, Mid+THP = Midazolam and tetrahydropalmatine, SEM = Standard Error of the Mean.

Fine Motor Movements

Similarly, a significant increase in fine motor movement of rats was found in the PTSD vehicle group compared to the control THP group $(\mathrm{P}<0.001)$; the control midazolam group $(\mathrm{P}<0.001)$; the control midazolam plus THP group 
$(\mathrm{P}<0.001)$; the PTSD THP group $(\mathrm{P}<0.001)$; the PTSD midazolam group $(\mathrm{P}=0.012)$; and the $\mathrm{PTSD}$ midazolam plus THP $(\mathrm{P}<0.001)$. Other significant increases in fine motor movements of rats were found in the control vehicle group compared to the control THP group $(\mathrm{P}<0.001)$; the control midazolam group $(\mathrm{P}<0.001)$; the control midazolam plus THP group $(\mathrm{P}<0.001)$; the PTSD THP group $(\mathrm{P}<0.001)$; the $\mathrm{PTSD}$ midazolam group $(\mathrm{P}=0.001)$; and the PTSD midazolam plus THP $(\mathrm{P}<0.001)$. Further
$(M=14.51+0.68)$ and the control vehicle group had the lowest mean time spent in zone $3(\mathrm{M}=10.35+1.429)$ (see Table 4 and Figure 6).

\section{Discussion}

The purpose of this study was to investigate THP and its effect on PTSD induced neurobehavior in the rodent model and to further corroborate this stringent PTSD rodent

Table 3. Table showing treatment groups, sample size, mean ratio of open arm time to total maze time (in seconds), the number of basic motor movements and number of fine motor movements on elevated plus maze.

\begin{tabular}{|l|c|c|c|c|}
\hline \multicolumn{1}{|c|}{ Group } & $\begin{array}{c}\text { Sample } \\
\text { Size }\end{array}$ & $\begin{array}{c}\text { Mean Ratio Open Arm/Total } \\
\text { Time } \pm \text { SEM }\end{array}$ & $\begin{array}{c}\text { Basic Motor } \\
\text { Movement } \pm \text { SEM }\end{array}$ & $\begin{array}{c}\text { Fine Motor Movement } \\
\pm \text { SEM }\end{array}$ \\
\hline Control Vehicle & 10 & $43.7 \pm 5.8^{*}$ & $1103.2 \pm 52.7$ & $794.3 \pm 33.9$ \\
\hline Control THP & 9 & $53.6 \pm 15.3$ & $222.4 \pm 53.5^{*}$ & $185.3 \pm 40.0^{*}$ \\
\hline Control Midazolam & 9 & $77.8 \pm 7.6^{*}$ & $391 \pm 109.4^{*}$ & $276 \pm 73.6^{*}$ \\
\hline Control Midazolam + THP & 9 & $39.9 \pm 11.3^{*}$ & $478.1 \pm 115.3^{*}$ & $366.3 \pm 84.6^{*}$ \\
\hline PTSD Vehicle & 9 & $25.2 \pm 4.2^{*}$ & $1017.4 \pm 73.3$ & $717.9 \pm 47.3$ \\
\hline PTSD THP & 10 & $34.7 \pm 11^{*}$ & $264.5 \pm 56.7^{*}$ & $208.4 \pm 41.8^{*}$ \\
\hline PTSD Midazolam & 10 & $39.7 \pm 9.3^{*}$ & $731.5 \pm 135.1^{*}$ & $499.2 \pm 89^{*}$ \\
\hline PTSD Midazolam + THP & 10 & $53.9 \pm 14.8$ & $130 \pm 54.3^{*}$ & $102.8 \pm 43.6^{*}$ \\
\hline
\end{tabular}

Data are presented as mean \pm standard error of the mean. SEM $=$ Standard Error of the Mean, THP $=$ tetrahydropalmatine, PTSD $=$ Post Traumatic Stress Disorder. ${ }^{*} \mathrm{P}<0.05$.

Table 4. Table showing treatment groups, sample size, mean time spent in zone 3 and standard error of the mean.

\begin{tabular}{|l|c|c|c|}
\hline \multicolumn{1}{|c|}{ Group } & Sample Size & Mean Zone 3 Time & Standard Error of the Mean \\
\hline Control Vehicle & 10 & 10.35 & 1.429 \\
\hline Control THP & 9 & 13.68 & 1.372 \\
\hline Control Midazolam & 9 & 14.51 & 0.680 \\
\hline Control Midazolam + THP & 9 & 13.41 & 0.869 \\
\hline PTSD Vehicle & 9 & 13.29 & 1.546 \\
\hline PTSD THP & 10 & 11.21 & 1.957 \\
\hline PTSD Midazolam & 10 & 13.61 & 1.345 \\
\hline PTSD Midazolam + THP & 10 & 13.89 & 0.922 \\
\hline
\end{tabular}

THP = tetrahydropalmatine, PTSD = Post Traumatic Stress Disorder.

significant increases in fine motor movement of rats were found in the PTSD midazolam group compared to the control THP group $(\mathrm{P}<0.001)$; the control midazolam group $(\mathrm{P}=0.011)$; the $\mathrm{PTSD}$ vehicle group $(\mathrm{P}=0.012)$; the PTSD THP group ( $\mathrm{P}=0.001)$; and the PTSD midazolam plus THP $(\mathrm{P}<0.001)$. Significant increases in fine motor movement of rats were also found in the control THP group compared to the control midazolam plus THP group $(\mathrm{P}=0.042)$; the control midazolam plus THP group compared to the PTSD midazolam plus THP group $(\mathrm{P}=0.003)$; and the control midazolam group compared to the PTSD midazolam plus THP group $(\mathrm{P}=0.045)$ (see Table 3 and Figure 5).

\section{Morris Water Maze}

In the Morris Water Maze test, there were no statistically significant differences found between groups when looking at latency, time, and entries to the platform area or Zone 3 (see Figure 2). The nonstressed midazolam group had the overall highest mean time spent in Zone 3 model. This was the first study evaluating THP in a PTSD model. The ability of THP administered to a rodent with induced PTSD to alleviate the symptoms of anxiety, locomotion, and memory was studied. Rats were separated into PTSD and non-stressed groups and administered various pharmacological agents. The PTSD induction model in which rats were exposed to a two-hour immobilization and tail-shock session over three days was validated in our study. This was evidenced by a significant increase in the ratio of open-arm time versus total time when comparing the control midazolam group and all PTSD treatment groups $(\mathrm{P}=0.014)$, revealing anxiety-like behavior in the rats that underwent PTSD conditioning.

The EPM was used to evaluate the amount of anxietylike behavior experienced by the rat (H. Falter, Persinger, \& Chretien, 1992; Rosa et al., 2000; Shepherd, Grewal, Fletcher, Bill, \& Dourish, 1994; Treit et al., 1993). During the 5-minute test, the number of entries into the open or closed arms, as well as the time spent in each arm, was a measure of anxiety-like behavior. Our results showed that 


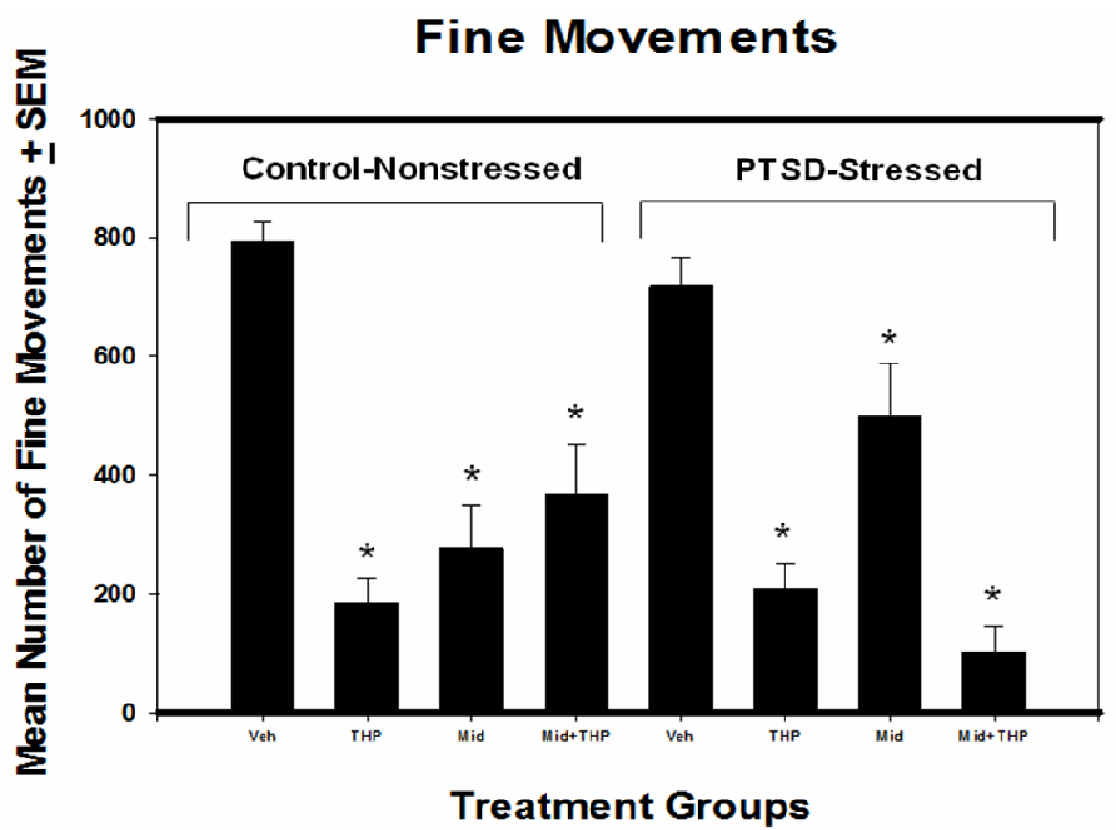

Figure 5. Bar graph representing the mean number of fine movements as recorded by the Motor monitor software on the Elevated Plus Maze. The X axis is the treatment groups and the $\mathrm{Y}$ axis shows the mean number of fine movements plus or minus the standard error of the mean. The asterisks show the groups that showed significance. Veh $=$ Vehicle, THP = tetrahydropalmatine, Mid $=$ Midazolam, Mid+THP = Midazolam and tetrahydropalmatine, SEM = Standard Error of the Mean.

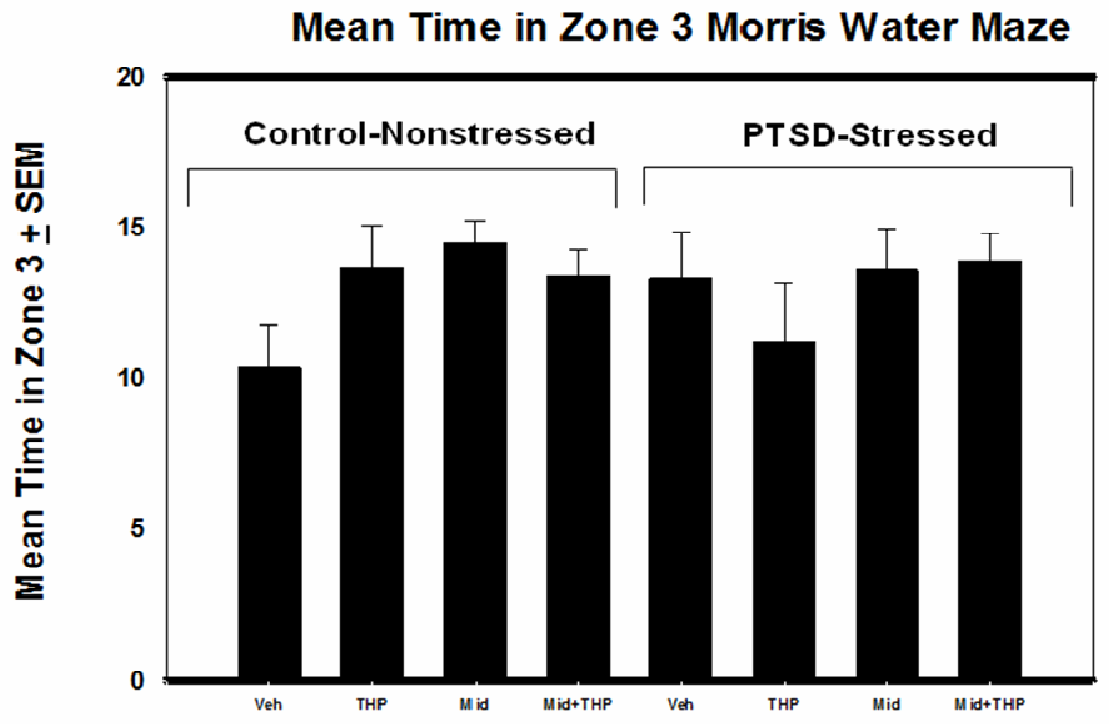

Treatment Groups

Figure 6. Bar graph representing the mean time spent in Zone 3 of Morris water maze plus or minus the standard error of the mean. The $\mathrm{X}$ axis is treatment groups and the $\mathrm{Y}$ axis is mean time spent in Zone 3 plus or minus the standard error of the mean. Veh = Vehicle, THP = tetrahydropalmatine, Mid = Midazolam, Mid+THP = Midazolam and tetrahydropalmatine, SEM = Standard Error of the Mean.

the control midazolam group had the higher mean $(M=77.8)$ entries into the open arm compared to all other groups. The PTSD vehicle group had the lowest number of entries ( $M=25.2)$. The addition of THP did not result in any significant difference between the groups with a mean of $(\mathrm{M}=34.7)$.

The MWM was used to investigate learning and memory in rats (Wenk, 2004). The time it takes the rats to find the hidden platform is the determinate of spatial memory. Our data showed no statistical significance with the use of THP, when evaluating distance, mean speed, and entries into the Zone 3 where the platform was located.

Overall, evaluation of the data collected in this study did not support our hypothesis that THP may ameliorate the 
symptoms of PTSD. However, our experimental model was validated through our implemented controls.

While a one-time dose was insufficient in providing a significant decrease in anxiety, a multi-dose regimen may yield more effective results. Future experiments should evaluate a multi-dose or prophylactic regimen. The timing of administration, such as multidose or prophylaxis, may yield different results. It is known that some treatments of PTSD (i.e. antidepressants) may require an extended period of time to affect neurobehavior (Dremencov et al., 2004; Gelenberg \& Chesen, 2000). Future studies of THP may utilize our current validated model with an extended dosing period, to obtain steady state for the period of time needed to alter neurobehavior.

\section{Conclusion}

PTSD is a devastating, debilitating, and costly neuropathologic outcome of war. It is critical that nurses and other health care professionals investigate treatments to ameliorate the neurobehavioral sequelae from PTSD. While the results in this study showed no significant difference between rats it validated the theoretic framework and PTSD Disease Induction Model. This model will be useful in future research applications. The neurobehavioral data gleaned from this study and future studies is critically important for the translation of bench research to clinical research in moving towards optimizing the treatment of patients with PTSD.

\section{Acknowledgments}

The researchers would like to acknowledge their families and the support they provided, as well as the US Army Graduate Program in Anesthesia Nursing faculty for their expertise and guidance. We would also like to thank Dr. Dale Glaser for his invaluable assistance with processing the data and the US Army Institute of Surgical Research for allowing us to conduct this research at their facility.

\section{Conflicts of Interest and Funding Source}

There are no conflicts of interest. This work has been funded and supported by the TriService Nursing Research Program.

\section{Disclaimer}

The views expressed in this article are those of the authors and do not reflect the official policy or position of the Department of the Army, Department of Defense, or the US Government.

\section{References}

American Psychiatric Association (Ed.). (2000). Diagnostic and statistical manual of mental disorders: DSM-IV-TR®. American Psychiatric Pub.

Ang-Lee, M. K., Moss, J., \& Yuan, C. S. (2001). Herbal medicines and perioperative care. Jama, 286(2), 208-216. http://dx.doi.org/10.1001/jama.286.2.208 PMid:11448284
Barnes P, B. B., Nahin R. (2008). National Health Statistics Reports. Complementary and Alternative Medicine Use among Adults and Children: United States, 2007. Number 12. Dec 10, 2008., Retrieved from http://nccam.nih.gov/news/camstats/2007/camsurvey_fs1.htm

Benedek, D. F., M. Zatzick, D. Ursano, R. (2009). Guideline Watch (March 2009): Practice Guideline for the Treatment of Patients With Acute Stress Disorder and Posttraumatic Stress Disorder. Retrieved from http://www.psychiatryonline.com/content.aspx?aID=156514

Ceremuga, T. E., Shellabarger, P., Persson, T., Fanning, M., Galey, P., Robinson, D., Bentley, M. (2013). Effects of tetrahydropalmatine on post-traumatic stress disorder-induced changes in rat brain gene expression. J Integr Neurosci, 12(4), 513-528. http://dx.doi.org/10.1142/S0219635213500313

Chan, P., Chiu, W. T., Chen, Y. J., Wu, P. J., \& Cheng, J. T. (1999). Calcium influx inhibition: possible mechanism of the negative effect of tetrahydropalmatine on left ventricular pressure in isolated rat heart. Planta Med, 65(4), 340-342. http://dx.doi.org/10.1055/s-1999-13998 PMid:10364840

Chang, C. K., \& Lin, M. T. (2001). DL-Tetrahydropalmatine may act through inhibition of amygdaloid release of dopamine to inhibit an epileptic attack in rats. Neurosci Lett, 307(3), 163-166. http://dx.doi.org/10.1016/S0304-3940(01)01962-0

Chueh, F. Y., Hsieh, M. T., Chen, C. F., \& Lin, M. T. (1995). DLtetrahydropalmatine-produced hypotension and bradycardia in rats through the inhibition of central nervous dopaminergic mechanisms. Pharmacology, 51(4), 237-244. http://dx.doi.org/10.1159/000139365 PMid:8577817

Dorman, T. (2001). Herbal medicine and anesthesia. Curr Opin Anaesthesiol, 14(6), 667-669. PMid:17019163. http://dx.doi.org/10.1097/00001503-200112000-00012

Dremencov, E., Nahshoni, E., Levy, D., Mintz, M., Overstreet, D. H., Weizman, A., \& Yadid, G. (2004). Dimensional complexity of the neuronal activity in a rat model of depression. Neuroreport, 15(12), 1983-1986. http://dx.doi.org/10.1097/00001756-200408260-00030 PMid:15305150

Eisenberg, D. M., Davis, R. B., Ettner, S. L., Appel, S., Wilkey, S., Van Rompay, M., \& Kessler, R. C. (1998). Trends in alternative medicine use in the United States, 1990-1997: results of a follow-up national survey. Jama, 280(18), 1569-1575. PMid:9820257. http://dx.doi.org/10.1001/jama.280.18.1569

Falter, H., Persinger, M. A., \& Chretien, R. (1992). Transient suppression of a secondary humoral response in rats is evoked by lithium-pilocarpineinduced limbic seizures. Pharmacol Biochem Behav, 43(1), 315-317. http://dx.doi.org/10.1016/0091-3057(92)90674-5

Falter, U., Gower, A. J., \& Gobert, J. (1992). Resistance of baseline activity in the elevated plus-maze to exogenous influences. Behav Pharmacol, 3(2), 123-128. http://dx.doi.org/10.1097/00008877-19920400000004 PMid:11224109

Flood, P. D. (2009). The stressed-out rat: a model for anesthetic prevention of post-traumatic stress disorder. Anesthesiology, 110(3), 447-448. $\quad$ http://dx.doi.org/10.1097/ALN.0b013e3181974fcc PMid:19204563.

Frick, K. M., Stillner, E. T., \& Berger-Sweeney, J. (2000). Mice are not little rats: species differences in a one-day water maze task. Neuroreport, 11(16), 3461-3465. PMid:11095500. http://dx.doi.org/10.1097/00001756-200011090-00013

Garrick, T., Morrow, N., Shalev, A. Y., \& Eth, S. (2001). Stress-induced enhancement of auditory startle: an animal model of posttraumatic stress disorder. Psychiatry, 64(4), 346-354. PMid:11822211. http://dx.doi.org/10.1521/psyc.64.4.346.18600

Gelenberg, A. J., \& Chesen, C. L. (2000). How fast are antidepressants? J Clin Psychiatry, 61(10), 712-721. PMid:11078031. 


\section{http://dx.doi.org/10.4088/JCP.v61n1002}

Glaser, D. (2010, Feb 24, 2010). [Proposed Statistical Analysis for Grant Proposal: Effects of Herbal Supplement administration on PTSDinduced changes in Rodent Behavior and Brain Gene Expression].

Henkes, H., Franz, M., Kendall, O., Monroe, J., Legaspi, A., LeDoux, J., Ceremuga, T. E. (2011). Evaluation of the anxiolytic properties of tetrahydropalmatine, a Corydalis yanhusuo compound, in the male Sprague-Dawley rat. AANA J, 79(4 Suppl), S75-80. PMid:22403971

Hong, Z., Fan, G., Le, J., Chai, Y., Yin, X., \& Wu, Y. (2006). Brain pharmacokinetics and tissue distribution of tetrahydropalmatine enantiomers in rats after oral administration of the racemate. Biopharm Drug Dispos, 27(3), 111-117. PMid:16400711. http://dx.doi.org/10.1002/bdd.489

Hu, J., Xie, J., Zhang, Y., Wang, J., \& Chen, R. (1994). [Effect of some drugs on electroacupuncture analgesia and cytosolic free $\mathrm{Ca} 2+$ concentration of mice brain]. Zhen Ci Yan Jiu, 19(1), 55-58. PMid:7834855

Jankowsi, K. (2010). PTSD and Physical Health. National Center for PTSD., Retrieved from http://www.ptsd.va.gov/professional/pages/ptsdphysical-health.asp

$\begin{array}{llll}\text { Jointcommission. (2010). 2009, } & \text { Retrieved }\end{array}$ http://www.jointcommission.org

Kaye, A. D., Kucera, I., \& Sabar, R. (2004). Perioperative anesthesia clinical considerations of alternative medicines. Anesthesiol Clin North America, 22(1), 125-139. http://dx.doi.org/10.1016/S0889-8537(03)00113-5

Lambert. (2008). The new ancient trend in medicine. Harvard Magazine. March-April 2002., Retrieved from http://www.harvardmagazine.com/on-line/030221.html

Lee, A., Chui, P. T., Aun, C. S., Lau, A. S., \& Gin, T. (2006). Incidence and risk of adverse perioperative events among surgical patients taking traditional Chinese herbal medicines. Anesthesiology, 105(3), 454-461. http://dx.doi.org/10.1097/00000542-200609000-00007 PMid:16931976

Lin, M. T., Chueh, F. Y., Hsieh, M. T., \& Chen, C. F. (1996). Antihypertensive effects of DL-tetrahydropalmatine: an active principle isolated from Corydalis. Clin Exp Pharmacol Physiol, 23(8), 738-742. http://dx.doi.org/10.1111/j.1440-1681.1996.tb01769.x PMid:8886500

Lin, M. T., Wang, J. J., \& Young, M. S. (2002). The protective effect of dltetrahydropalmatine against the development of amygdala kindling seizures in rats. Neurosci Lett, 320(3), 113-116. http://dx.doi.org/10.1016/S0304-3940(01)02508-3

Lister, R. G. (1987). The use of a plus-maze to measure anxiety in the mouse. Psychopharmacology (Berl), 92(2), 180-185. http://dx.doi.org/10.1007/BF00177912

McPherson, F., \& Schwenka, M. A. (2004). Use of complementary and alternative therapies among active duty soldiers, military retirees, and family members at a military hospital. Mil Med, 169(5), 354-357. PMid:15185998

Nutt, D. J., \& Malizia, A. L. (2001). New insights into the role of the GABA(A)-benzodiazepine receptor in psychiatric disorder. $\mathrm{Br} J$ Psychiatry, 179, 390-396. http://dx.doi.org/10.1192/bjp.179.5.390 PMid:11689393

Pellow, S., Chopin, P., File, S. E., \& Briley, M. (1985). Validation of open:closed arm entries in an elevated plus-maze as a measure of anxiety in the rat. $J$ Neurosci Methods, 14(3), 149-167. http://dx.doi.org/10.1016/0165-0270(85)90031-7

Rosa, V. P., Vandresen, N., Calixto, A. V., Kovaleski, D. F., \& Faria, M. S. (2000). Temporal analysis of the rat's behavior in the plus-maze: effect of midazolam. Pharmacol Biochem Behav, 67(1), 177-182. http://dx.doi.org/10.1016/S0091-3057(00)00316-6

Sabar, R., Kaye, A. D., \& Frost, E. A. (2001). Perioperative considerations for the patient on herbal medicines. Middle East J Anesthesiol, 16(3),
287-314

Servatius, R. J., Beck, K. D., Moldow, R. L., Salameh, G., Tumminello, T. P., \& Short, K. R. (2005). A stress-induced anxious state in male rats: corticotropin-releasing hormone induces persistent changes in associative learning and startle reactivity. Biol Psychiatry, 57(8), 865$872 . \quad$ http://dx.doi.org/10.1016/j.biopsych.2005.01.015 PMid:15820707

Servatius, R. J., Ottenweller, J. E., \& Natelson, B. H. (1995). Delayed startle sensitization distinguishes rats exposed to one or three stress sessions: further evidence toward an animal model of PTSD. Biol Psychiatry, 38(8), 539-546. http://dx.doi.org/10.1016/0006-3223(94)00369-E

Shader, R. I., \& Greenblatt, D. J. (1993). Use of benzodiazepines in anxiety disorders. $N$ Engl J Med, 328(19), 1398-1405. PMid:8292115. http://dx.doi.org/10.1056/NEJM199305133281907

Shepherd, J. K., Grewal, S. S., Fletcher, A., Bill, D. J., \& Dourish, C. T. (1994). Behavioural and pharmacological characterisation of the elevated "zero-maze" as an animal model of anxiety. Psychopharmacology (Berl), 116(1), 56-64. http://dx.doi.org/10.1007/BF02244871

Shiner, B., Drake, R. E., Watts, B. V., Desai, R. A., \& Schnurr, P. P. (2012). Access to VA services for returning veterans with PTSD. Mil Med, 177(7), 814-822. http://dx.doi.org/10.7205/MILMED-D-12-00009 PMid:22808888

Smith, T. C., Ryan, M. A., Smith, B., Reed, R. J., Riddle, J. R., Gumbs, G. R., \& Gray, G. C. (2007). Complementary and alternative medicine use among US Navy and Marine Corps personnel. BMC Complement Altern Med, 7, 16. http://dx.doi.org/10.1186/1472-6882-7-16 PMid:17506899 PMCid:PMC1884175

Treit, D., Menard, J., \& Royan, C. (1993). Anxiogenic stimuli in the elevated plus-maze. Pharmacol Biochem Behav, 44(2), 463-469. http://dx.doi.org/10.1016/0091-3057(93)90492-C

Ursano RJ, Bell C, Eth S, Friedman M, Norwood A, Pfefferbaum B, Pynoos JD, Zatzick DF, Benedek DM, McIntyre JS, Charles SC, Altshuler K, Cook I, Cross CD, Mellman L, Moench LA, Norquist G, Twemlow SW, Woods S, \& Yager J (2004). Practice guideline for the treatment of patients with acute stress disorder and posttraumatic stress disorder. $\mathrm{Am} \mathrm{J}$ Psychiatry, 161(11 Suppl), 3-31. PMid:15617511

Ursano, R. J., Zhang, L., Li, H., Johnson, L., Carlton, J., Fullerton, C. S., \& Benedek, D. M. (2009). PTSD and traumatic stress from gene to community and bench to bedside. Brain Res, 1293, 2-12. http://dx.doi.org/10.1016/j.brainres.2009.03.030 PMid:19328776

Wenk, G. L. (2004). Assessment of spatial memory using the radial arm maze and Morris water maze. Curr Protoc Neurosci, Chapter 8, Unit 8 5A. http://dx.doi.org/10.1002/0471142301.ns0805as26

Zhang, L., Zhou, R., Xing, G., Hough, C. J., Li, X., \& Li, H. (2006). Identification of gene markers based on well validated and subcategorized stressed animals for potential clinical applications in PTSD. Medical Hypotheses, 66(2), 309-314. http://dx.doi.org/10.1016/j.mehy.2005.06.034

Zhu, X. Z. (1991). Development of natural products as drugs acting on central nervous system. Mem Inst Oswaldo Cruz, 86 Suppl 2, 173-175. http://dx.doi.org/10.1590/S0074-02761991000600039. 